\title{
Information Resources Economy in Satellite Systems based on New Microwave Polarizers with Tunable Posts
}

\author{
Stepan Piltyay ${ }^{1}$, Andrew Bulashenko ${ }^{1}$, Hanna Kushnir ${ }^{1}$, Oleksandr Bulashenko ${ }^{1}$ \\ ${ }^{1}$ Igor Sikorsky Kyiv Polytechnic Institute \\ 37, Prospect Peremohy, Kyiv, 03056, Ukraine
}

DOI: $10.22178 /$ pos.64-6

LCC Subject Category:

TK5101-6720

Received 05.10.2020

Accepted 25.11.2020

Published online 30.11.2020

Corresponding Author:

Stepan Piltyay,

crosspolar@ukr.net

(c) 2020 The Authors. This article is licensed under a Creative

Commons Attribution 4.0

License @ (1)

Abstract. One of the fundamental problems of modern digital telecommunications is the economy of digital information and frequency resources, which are highly limited. The introduction of novel telecommunication systems and $5 \mathrm{G}$ networks requires searching for principal solutions for the economy and reusing the frequency spectrum. Therefore, modern wireless mobile, terrestrial, and satellite systems use various new technologies to increase communication channels' information capacity for the economy of limited frequency resources. One of the most effective ways to reuse the information system's operating frequency band is to apply antennas with polarisation signal processing. Such systems provide the possibility to transmit and to receive simultaneously signals with different types of polarisation.

Consequently, the application of electromagnetic waves with two orthogonal polarisations improves wireless systems' information characteristics for various purposes. This allows doubling the information capacity of mobile, terrestrial, and satellite communication channels. Also, polarisation processing is carried out in meteorological and radar systems to receive, transmit, and process information. The essential elements of such systems are microwave polarisers and orthomode transducers. The electromagnetic characteristics of these devices affect the aspects of the whole system significantly. Main electromagnetic factors include phase, matching, and polarisation parameters. The article presents the development of a compact tunable polarizer based on a square waveguide with three posts. The developed polariser operates in the X-band from $8.0 \mathrm{GHz}$ to 8.5 $\mathrm{GHz}$. Created a mathematical model of the polariser is based on the scattering and transmission matrices. To verify the developed theoretical model's correctness, the calculation of all characteristics was also performed numerically using the finite integration technique. The developed compact polariser based on a square waveguide with three posts allows tuning it's matching and polarisation characteristics by changing all posts' heights. The developed polariser's main advantages are small dimensions, tuning options, and aspects of polarisation transformation.

Keywords: information resources; satellite systems; circular polarization; microwave polarizer; waveguide polarizer; tunable polarizer; frequency spectrum; differential phase shift; cross-polar discrimination; axial ratio.

\section{INTRODUCTION}

Nowadays, the increase in communication channels' information capacity and their energy efficiency are essential crucial problems. In particular, in $5 \mathrm{G}$ networks, this problem resulted in the occurrence and widespread application of D2D direct connection technologies [1, 2], M2M technologies [3], and OFDM technology [4, 5]. In modern satellite systems and radars, polarisation signal processing is effectively applied to reuse the frequency resources $[6,7]$.
The key elements of antenna systems engaged in dual-polarization signal processing are microwave devices of feeds. Namely, polarisation processing is carried out by waveguide polarizers in combination with orthomode transducers. Polarisers introduce the necessary phase shift and convert circular polarisations into linear ones. In turn, the orthomode transducer separates linearly polarised signals and directs them to two highly isolated waveguide channels $[8,9]$. The modern designs 
of polarizers are realized in the form of waveguide structures with irises $[10,11,12]$, ridges $[13,14,15,16,17]$, posts $[18,19,20,21$, $22,23,24]$, thin metal septums $[25,26]$ and slots $[27,28]$. The waveguide polarizers with posts and irises operate similarly to the post and iris waveguide phase shifters applied in phased array antennas and other systems $[29,30,31,32,33$, $34,35,36]$.

In paper [8], the authors presented the design and simulated characteristics of a novel highperformance coherent ortomode transducer for new antenna designs with polarisation processing of radio signals. Developed orthomode transducer provides the following features in the operating satellite frequency bands $3.4-4.2 \mathrm{GHz}$ and 10.7-12.8 GHz: VSWR for the main modes of horizontal and vertical polarisations are less than 1.06, the differential phase shift is within the range $90^{\circ} \pm 1^{\circ}$, the XPD is higher than $70 \mathrm{~dB}$. The author of the article [9] developed a broadband coherent orthomode transducer based on a coaxial quad-ridged waveguide for the operating frequency range 3.4-5.4 GHz. The orthomode transducer's reflection coefficient does not exceed $-24 \mathrm{~dB}$; the cross-polar discrimination (XPD) exceeds $38 \mathrm{~dB}$. Developed orthomode transducer is used in dual-polarization multiband antennas.

The article [10] proposes a new waveguide polarizer with irises for the operating C-band. The $30 \%$ operating fractional bandwidth provides a reflection coefficient of $-40 \mathrm{~dB}$ and a cross-polar discrimination level of $-35 \mathrm{~dB}$. In articles [10, 11], a polarizer based on a square waveguide with irises for the Ku-frequency band was developed. The square waveguide polarizer with four irises provides VSWR less than 1.24. Its differential phase shift is $90^{\circ} \pm 3.5^{\circ}$. The axial ratio is less than $0.53 \mathrm{~dB}$. The XPD is higher than $30.3 \mathrm{~dB}$. In [13], the authors used the transverse-modal matching technique in partial regions to analyze coaxial ridged waveguides used to develop the polarisation processing devices. The article [14, $15]$ is devoted to considering eigenmodes of coaxial quad-ridged waveguides utilizing integral equations. This method allows taking into account the singular behavior of the fields on the edges of waveguides. Calculations confirm the reliability of the obtained results based on the finite differences technique. The article [16] presents the feed system's design for reflector antennas of dual circular polarisation satellite communication appliances. The feed system has been optimized for the operation in extended C- band 3.4-4.8 GHz. VSWR of the development system is less than 1.14, and its XPD is higher than $30 \mathrm{~dB}$. Paper [17] contains the development of a mathematical model of sectoral ridged waveguides using the integral equation technique.

The article [18] contains wave propagation in periodically loaded waveguide structures with cylindrical posts. Theoretical and experimental investigations of semi-periodic systems and their scattering matrices are performed. Article [19] offers the results of testing and numerical simulation of the reactance of posts in a circular waveguide. The reactance is a function of the waveguide and post dimensions and frequency, and the results presented are useful in the design of a variety of circular waveguide devices. The paper [20] shows scattering characteristics of a radially directed thin post in a circular waveguide using moments. Electric-type dyadic Green's function has been used to compute the scattered field in a circular waveguide considering the current variation in the post's axial direction. In the article [21], the authors analyzed three transverse cylindrical posts in a rectangular waveguide. It is shown that a relatively large shunt reactance range is achievable compared to that from a single variable-length post. The authors of [22] proposed a high-speed electromagnetic analysis of substrate integrated waveguides and substrate integrated slab waveguides. The developed method is used for the accurate and fast analysis of structures composed of metallic and dielectric posts in a parallel-plate waveguide environment. The article [23] analyzed functional post-wall waveguides formed by periodically distributed dielectric centers. The developed formulation is accurate and numerically very fast. Our investigations' final goal is to realize the available dielectric post-wall waveguide-based filters, which are expected to have a practical application in the THz region. A compact circular waveguide polarizer with a higher-order input mode (TM01) is presented in this paper [24]. The proposed design consists of a triangular metallic plate for TM01-TE11 (linearly polarised) mode conversion and metallic posts loading for linear TE11 to circular TE11 polarisation conversion.

The article [27] presents a polariser's design in a circular waveguide with irises realized using slots. The polariser can be reconfigured by rotating the irises relative to each other, providing the polarisation plane's rotation up to cross-one. Being relatively narrowband, the polarizer has a longitudinal dimension $\lambda_{0} / 50-\lambda_{0} / 10$. Article [28] presents the design, development, and characterization of compact wideband three-dimensional 
(3-D) printed circular waveguide-based polariser operating in Ka-band (28-34 GHz). The polariser structure is investigated using fundamental and higher-order modes, based on which a simplified equivalent structure is derived, giving physical insight into its mechanism of operation. The design consists of a pair of radially opposite grooves inside a circular waveguide and excited using a coaxial probe, making the design simple and highly compact compared to other conventional circular polarizers.

The article [25] presents a novel broadband septum polariser with a relative bandwidth of $37.8 \%$. It is enabled by using an equilateral triangular standard port waveguide, which guarantees the most extensive possible frequency range between fundamental and next higher-order mode cutoff. The authors developed polarisers in the field of 75-110 GHz and 18-26 GHz. Such polarizers provided the axial ratio remains below $1.3 \mathrm{~dB}$, whereas the input port isolation and the input return loss exceed 17 and $15 \mathrm{~dB}$, respectively. The authors [26] developed and optimized Q- and K-band waveguide polarizers with longitudinal septums of constant thicknesses. The optimal designs and their electromagnetic performance were analyzed for fractional bandwidths from $5 \%$ to $20 \%$ using the frequency domain's finite element method.

Article [29] presents a new phase shifter with two waveguide posts based on substrate integrated waveguide technique. Phase shifting is achieved by changing the diameter and metallic inductive positions inserted in the substrate integrated waveguide substrate. In article [30], a tunable phase shifter's design in a waveguidebased on two metal posts is proposed. The measured return loss and phase performances of this prototype are compared with the phase shifter's simulated full-wave response. The proposed waveguide component shows a great application potential in beam steering phased arrays implemented in waveguide technology.

The performed review demonstrates that polarisers based on a waveguide with posts is the simplest from the design point of view and provides the tuning option. It can improve the economy of information resources in satellite antenna systems. Therefore, this article is devoted to developing a new mathematical model for a polariser based on a square waveguide with three posts. Such a model allows performing the analysis and optimization of matching and polarisation characteristics.

\section{RESULTS}

\section{Mathematical model of tunable waveguide polarizer}

The design of the waveguide polarizer is shown in Figure 1. The structure contains two posts of height $h_{1}$ and diameter $d$, one position of height $h_{2}$ and diameter $d$, the distance between the centers is $l$. Moreover, the height of the central post $h_{2}$ is greater than the other posts $h_{1}$.

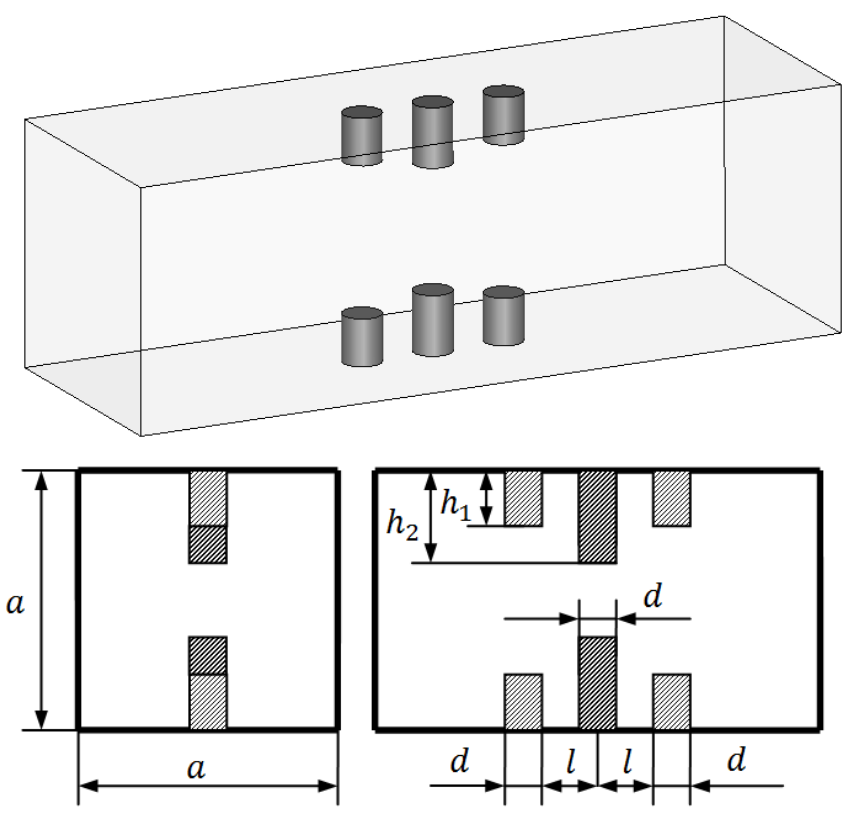

Figure 1 - Polariser design based on a waveguide with three posts

The presence of a cylindrical post allows you to adjust the device's characteristics by changing the post's length.

Figure 2 shows the electric field vectors' spatial location for vertical and horizontal polarisations at the square waveguide polariser's ports.

We represent a polariser with an equivalent circuit using the theory of microwave circuits (Figure 3). Figure 3a shows an equivalent circuit of a polariser model with three capacitive posts. Figure $3 \mathrm{~b}$ shows an equivalent circuit of a polariser model with three inductive posts. The identical circuit model with inductive seats will have only one regular transmission line [31-32]. The posts are perpendicular to the electric field lines, and the bases are not high relative to the wall size.

Thin inductive posts weakly influence the electric field vector's fundamental electromagnetic mode perpendicular to the post axis. Consequently, the equivalent circuit of a waveguide with inductive posts is as shown in Figure $3 \mathrm{~b}$. 

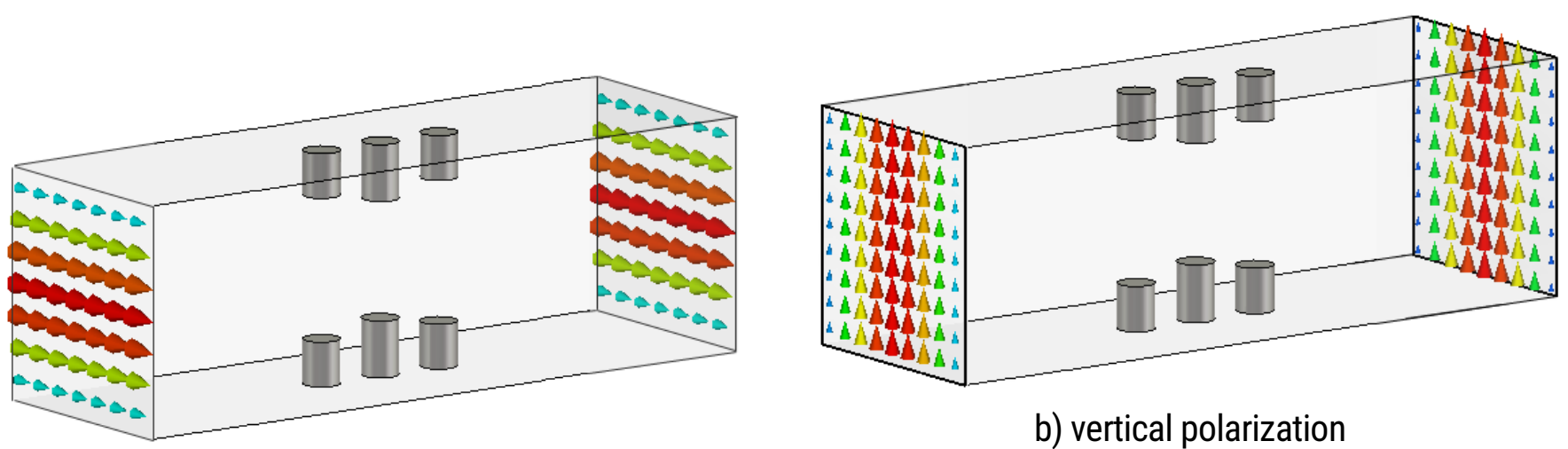

b) vertical polarization

a) horizontal polarization

Figure 2 - Electric field vectors at the ports of the square waveguide polariser

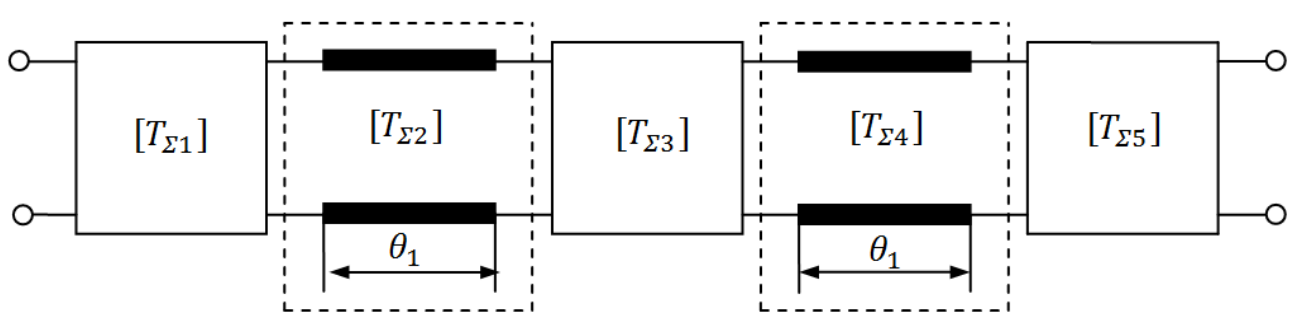

a)
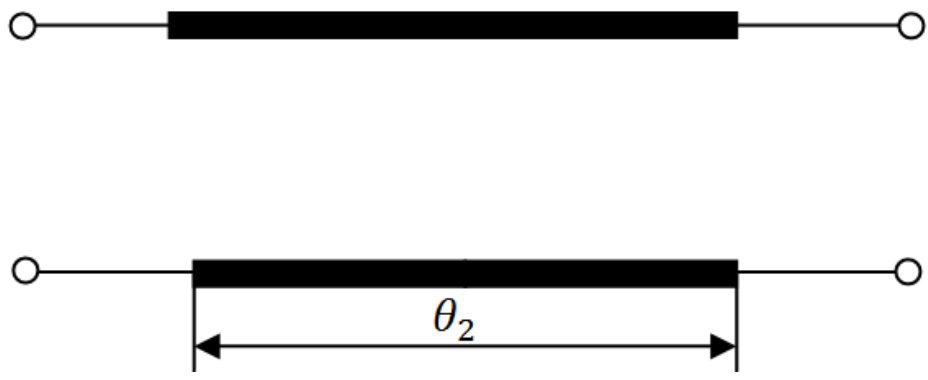

b)

Figure 3 - Equivalent circuit models of the waveguide polariser

a) with three capacitive posts; b) with three inductive posts

The following expression connects the wave scattering and transmission matrices of the two-port device (1):

$$
\left[S_{\Sigma}\right]=\left[\begin{array}{ll}
S_{\sum 11} & S_{\Sigma 12} \\
S_{\sum 21} & S_{\sum 22}
\end{array}\right]=\frac{1}{T_{\sum 11}}\left[\begin{array}{cc}
T_{\sum 21} & |T| \\
1 & -T_{\sum 12}
\end{array}\right],
$$

where $|T|$ is a determinant of the transmission wave matrix.

We form general wave scattering matrices based on the microwave theory [36], having divided the equivalent circuit of the polariser into smaller courses. In the case of capacitive posts (Figure 3a), we obtain (2):

$$
\left[T_{\Sigma}\right]=\left[T_{1}\right] \cdot\left[T_{2}\right] \cdot\left[T_{3}\right] \cdot\left[T_{4}\right] \cdot\left[T_{5}\right]=\left[\begin{array}{ll}
T_{\sum 11} & T_{\sum 12} \\
T_{\sum 21} & T_{\sum 22}
\end{array}\right],
$$

where

$$
\begin{aligned}
& {\left[T_{1}\right]=\left[T_{5}\right]=\frac{1}{2}\left[\begin{array}{cc}
2+Y_{p 1} & -Y_{p 1} \\
-Y_{p 1} & 2-Y_{p 1}
\end{array}\right],} \\
& {\left[T_{3}\right]=\frac{1}{2}\left[\begin{array}{cc}
2+Y_{p 2} & -Y_{p 2} \\
-Y_{p 2} & 2-Y_{p 2}
\end{array}\right],}
\end{aligned}
$$


$\left[T_{2}\right]=\left[T_{4}\right]=\left[\begin{array}{cc}e^{j \theta_{1}} & 0 \\ 0 & e^{-j \theta_{1}}\end{array}\right]$,

where $Y_{p 1}$ and $Y_{p 2}$ are the conductivity of the posts, $\theta_{1}$ is electric line length.

The electric length of a regular transmission line in the case of capacitive posts:

$$
\theta_{1}=\frac{2 \pi l}{\lambda_{g}}
$$

where $\lambda_{g}$ is the wavelength in the waveguide.

The wavelength in the waveguide:

$$
\lambda_{g}=\frac{\lambda_{0}}{\sqrt{1-\left(\frac{\lambda_{0}}{\lambda_{c}}\right)^{2}}},
$$

where $\lambda_{0}$ is the wavelength in the free space; $\lambda_{C}$ is the cutoff wavelength.

The expression determines the conductivity of the post [33]:

$$
Y_{p}=\frac{j \pi \lambda_{0} \lambda_{g}\left[1-\cos \left(k h_{p}\right)\right]^{2}}{a^{2} k(\mathrm{a}-\mathrm{r})\left(2+\cos \left(2 k h_{p}\right)\right)-\ln (\mathrm{a} / \mathrm{r}) \sin \left(2 k h_{p}\right)},
$$

where $a$ is the length of the wall of a square waveguide; $h_{p}$ is the height of the post in the waveguide; $k$ is wave number; $r$ is post radius.

Figure 4 presents a capacitive post in a rectangular waveguide.

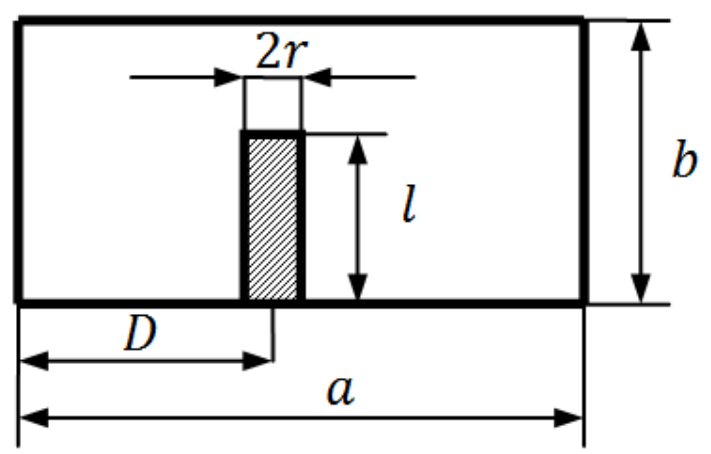

Figure 4 - Capacitive post in a rectangular waveguide
Figure 5 shows the dependence of the module of the conductivity of the posts on the frequency.

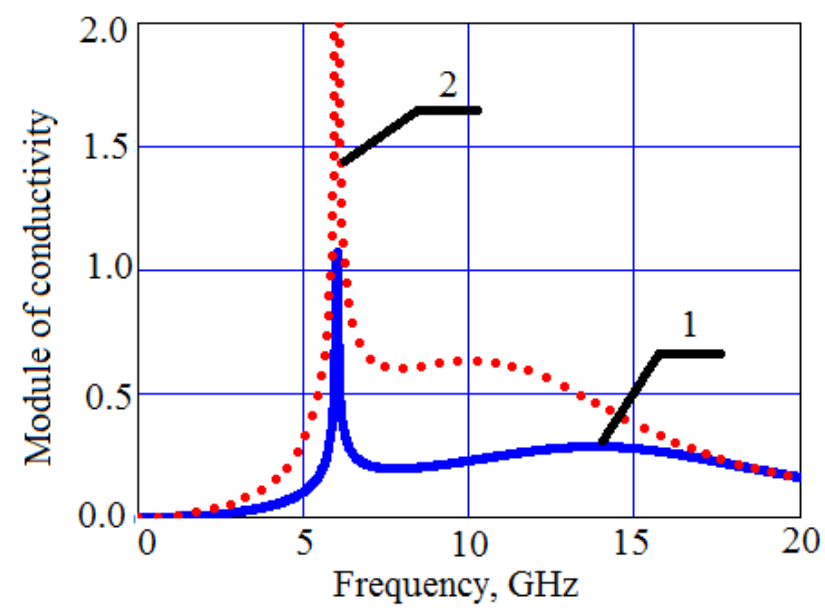

Figure 5 - Dependence of the module of the conductivity on frequency

In Figure 5, we can see that the module of the conductivity of the middle post 2 is greater than the module of the conductivity of the extreme point of curve 1 . This indicates that the medium post has a more substantial effect on the electromagnetic characteristics of the polariser.

In the case of inductive posts, the total wave transmission matrix is determined as follows:

$$
\left[T_{\Sigma}\right]=\left[\begin{array}{cc}
e^{j \theta_{2}} & 0 \\
0 & e^{-j \theta_{2}}
\end{array}\right]=\left[\begin{array}{cc}
T_{\sum 11} & T_{\sum 12} \\
T_{\sum 21} & T_{\sum 22}
\end{array}\right]
$$

where $\theta_{2}$ is electric line length.

The electric length of a regular transmission line in the case of the inductive posts is as follows:

$$
\theta_{2}=\frac{2 \pi l_{2}}{\lambda_{g}}, l_{2}=2 l+4 r
$$

The main characteristics of the polariser are as follows [34, 35]: phase-frequency dependences, matching, and polarisation characteristics. Phase and matching characteristics are the differential phase shift and the voltage stand wave ratio (VSWR). The polarising elements of a polariser are the axial ratio and the cross-polar discrimination (XPD). 
The expression determines the differential phase shift:

$$
\Delta \varphi=\varphi_{\sum 21 . C}-\varphi_{\sum 21 . L},
$$

where $\varphi_{\Sigma 21 . C}$ is a phase of the parameter $S_{21 \Sigma C}$ of the total wave scattering matrix for the model with capacitances; $\varphi_{\sum 21 . L}$ is a phase of the parameter $\mathrm{S}_{21 \Sigma L}$ of the general wave scattering matrix for the model with inductances.

The formula determines VSWR:

$$
V S W R=\left[1+\left|S_{11}\right|\right] /\left[1-\left|S_{11}\right|\right] .
$$

The axial ratio is determined as follows:

$r=10 \lg \left(\frac{A^{2}+B^{2}+\sqrt{A^{4}+B^{4}+2 A^{2} B^{2} \cos (\Delta \varphi)}}{A^{2}+B^{2}-\sqrt{A^{4}+B^{4}+2 A^{2} B^{2} \cos (\Delta \varphi)}}\right)$,

where $A=1, B=\left|S_{21}\right|$.

The formula calculates XPD:

$$
X P D=20 \lg \left[\left(10^{0.05 r}+1\right) /\left(10^{0.05 r}-1\right)\right] .
$$

Figure 6 shows the differential phase shift characteristics of the mathematical model, and Figure 7 shows the matching parts of this model.

Figure 6 demonstrates that the maximum deviation of the differential phase shift from $90^{\circ}$ is $4.7^{\circ}$. Figure 7 shows that the full value of VSWR is 1.29 .

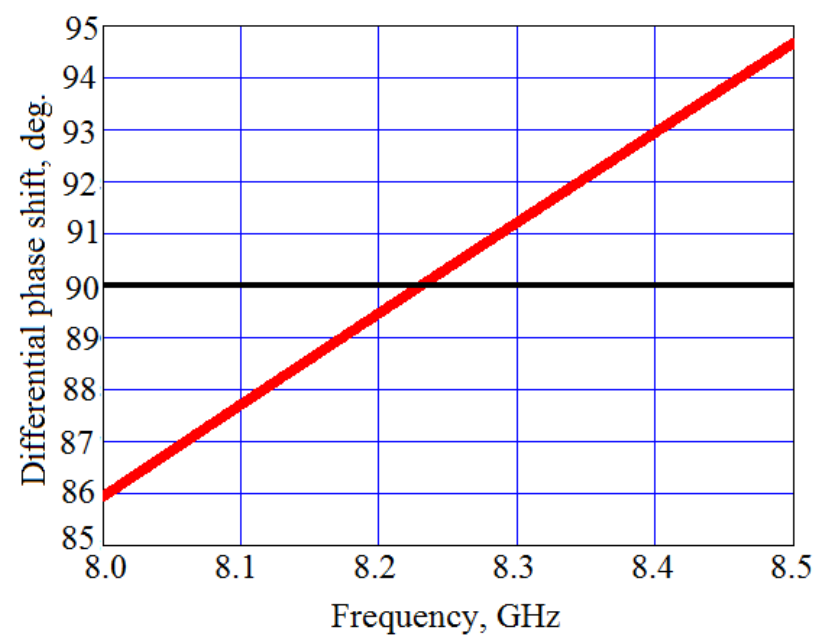

Figure 6 - Dependence of the differential phase shift of the polariser

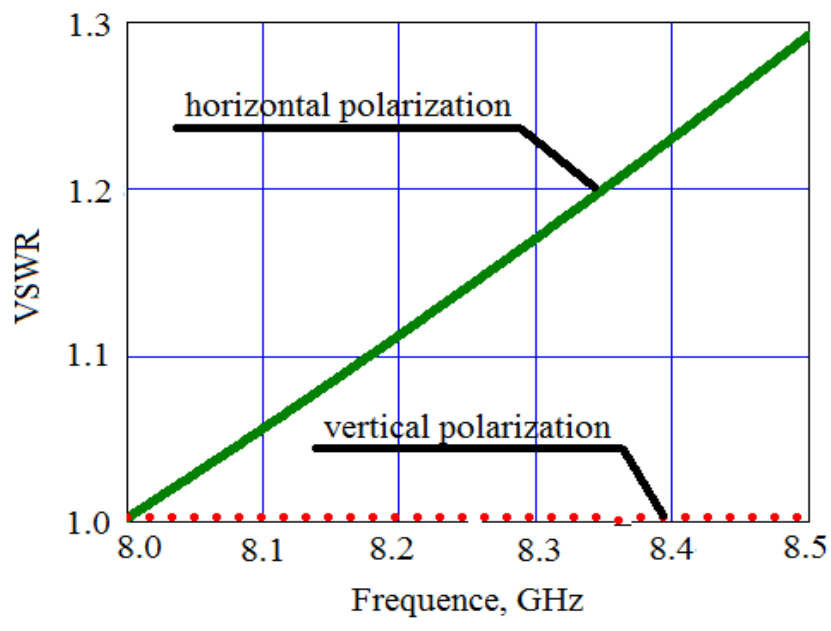

Figure 7 - Matching characteristic of the mathematical model

Figure 8 shows the polarisation characteristics of the mathematical model. Figure 8 represents the axial ratio's dependence on the frequency, and Figure $8 \mathrm{~b}$ illustrates the support of the XPD on the frequency.

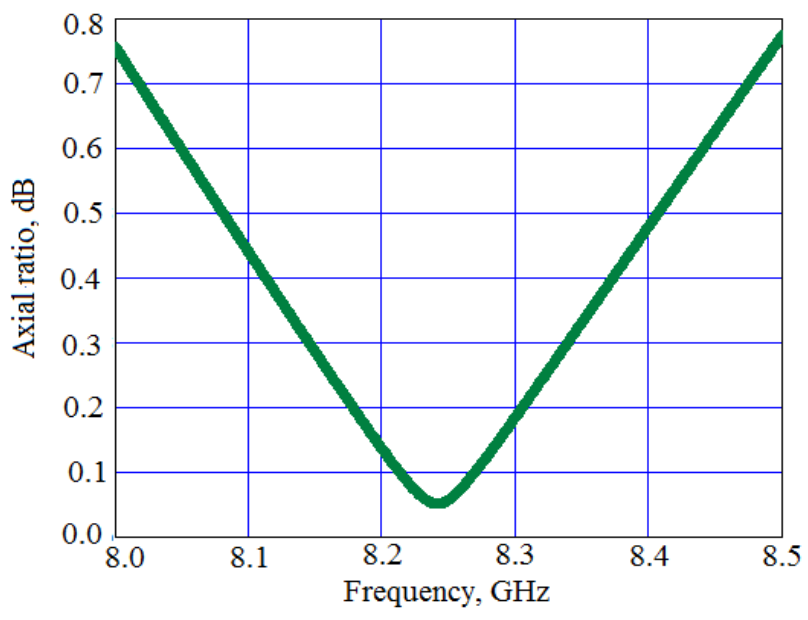

a)

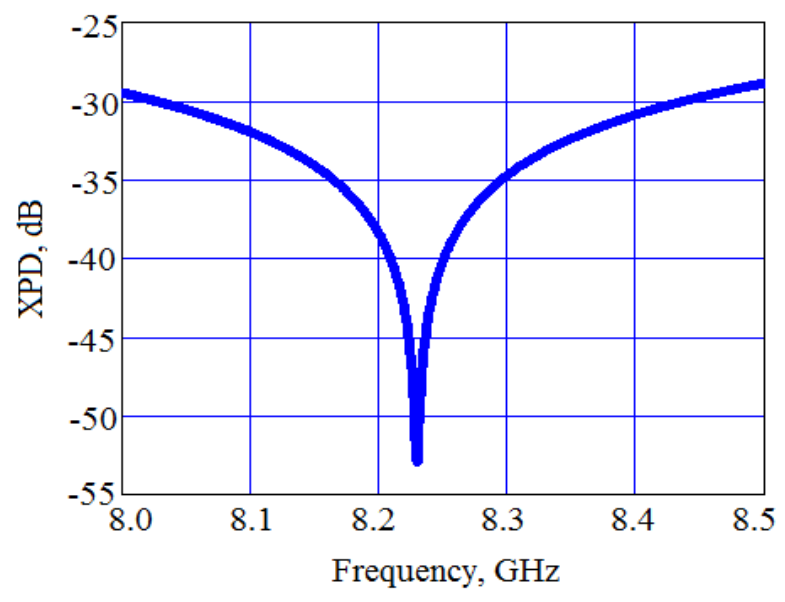

b)

Figure 8 - Polarisation characteristics of the mathematical model 
Figure 8a contains the axial ratio's dependence on the frequency, and Figure $8 \mathrm{~b}$ includes the reliance of the XPD on the frequency. In Figure 8, we see that at a frequency of $8.5 \mathrm{GHz}$ the axial ratio acquires its maximum value of $0.77 \mathrm{~dB}$. Also, at this frequency, the XPD receives a maximum weight of $29 \mathrm{~dB}$.

Thus, within the operating frequency range of 8.0-8.5 GHz, the optimized polariser based on a square waveguide with three posts provides the following characteristics: VSWR for the main modes of horizontal and vertical polarisation is less than 1.29, the differential phase shift is within $90^{\circ} \pm 4.7^{\circ}$, the axial is less than $0.77 \mathrm{~dB}$, the XPD is higher than $29 \mathrm{~dB}$.

\section{Analysis of the model based on the finite integration technique}

Figure 9 and Figure 10 show the phase and matching characteristics of the polariser. Figure 9 contains the differential phase shift's dependence on the frequency, and Figure 10 includes the support of VSWR on the frequency in the operating frequency range from $8.0 \mathrm{GHz}$ to $8.5 \mathrm{GHz}$.

Figure 9 demonstrates that the maximum deviation of the differential phase shift from $90^{\circ}$ is 5.2 . Figure 10 shows that the full value of VSWR is 1.3 .

Figure 11 shows the device's polarization characteristics in the operating frequency range from $8.0 \mathrm{GHz}$ to $8.5 \mathrm{GHz}$. Figure 11 contains the axial ratio's dependence on the frequency, and Figure $11 \mathrm{~b}$ includes the reliance of the XPD on the frequency. The Figure shows that at a frequency of $8.0 \mathrm{GHz}$, the axial ratio acquires its maximum value of $0.81 \mathrm{~dB}$. Also, at this frequency, the XPD accepts a maximum weight of $31 \mathrm{~dB}$.

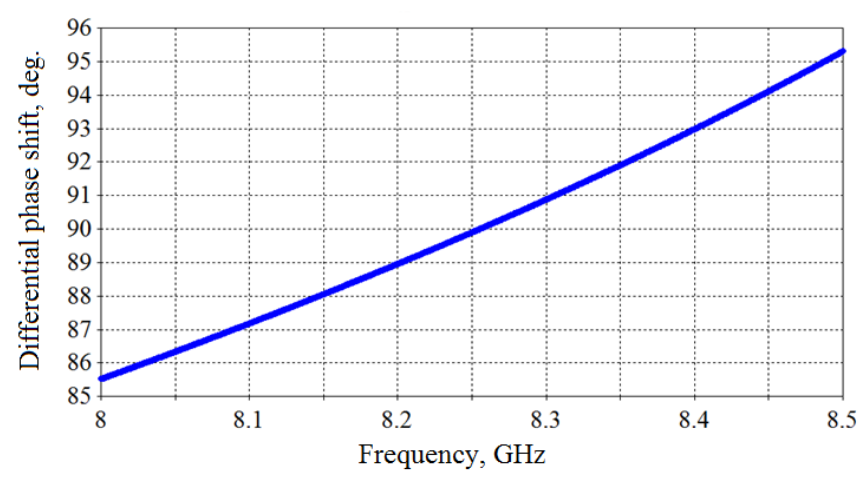

Figure 9 - Dependence of differential phase shift on frequency

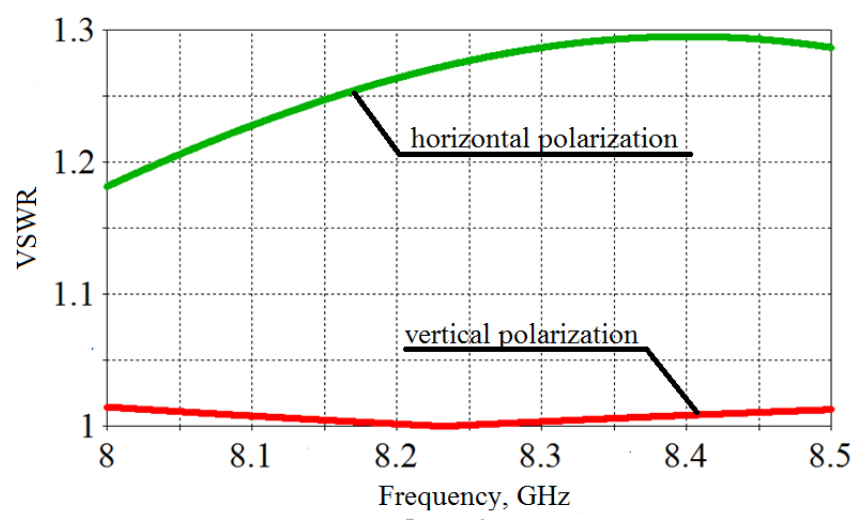

Figure 10 - Dependence of VSWR on frequency

Figure 11a shows that the axial ratio's minimum value is $0.06 \mathrm{~dB}$ at a frequency of $8.25 \mathrm{GHz}$. At the same frequency, the XPD is $48.4 \mathrm{~dB}$. At the minimum frequency of the range, the axial ratio has a value of $0.68 \mathrm{~dB}$, and the XPD is equal to $28 \mathrm{~dB}$.

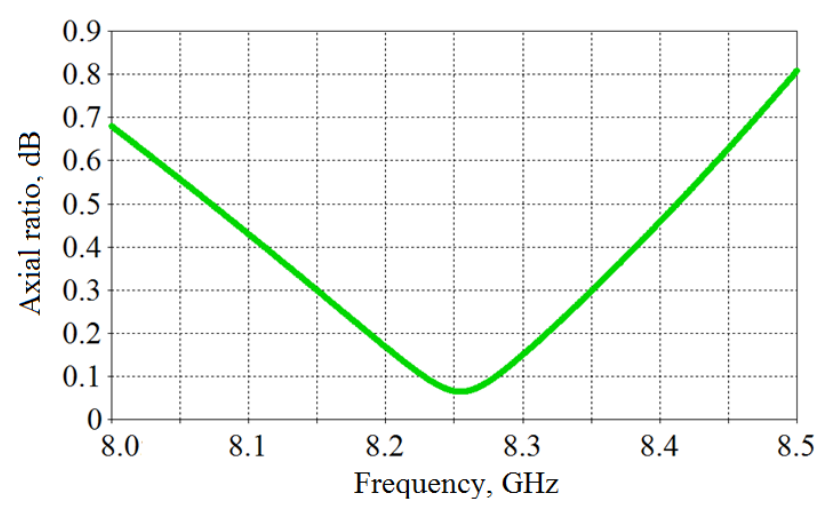

a)

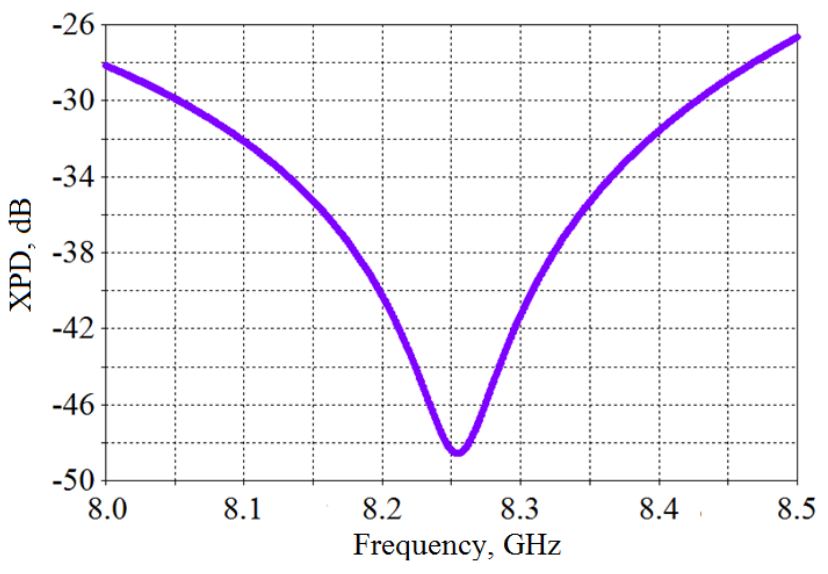

b)

Figure 11 - Polarisation characteristics of the prototype

Thus, within the operating frequency range of 8.0-8.5 GHz, the optimized polariser based on a square waveguide with three posts provides the following characteristics: VSWR for the main 
modes of horizontal and vertical polarisation is less than 1.3, the differential phase shift is within $90^{\circ} \pm 5.2^{\circ}$, the axial is less than $0.81 \mathrm{~dB}$, the XPD is higher than $26.5 \mathrm{~dB}$.

\section{Comparison of both theoretical models}

The optimized polariser sizes are summarised in Table 1.

Table 1 - Sizes of the optimal $X$-band waveguide iris polarizer obtained by the developed mathematical technique and by the finite integration technique

\begin{tabular}{|l|c|c|}
\hline \multicolumn{1}{|c|}{ Size name } & $\begin{array}{c}\text { Mathematical } \\
\text { model }\end{array}$ & $\begin{array}{c}\text { Numerical } \\
\text { model }\end{array}$ \\
\hline $\begin{array}{l}\text { Size of square } \\
\text { waveguide walls, mm }\end{array}$ & $\mathrm{a}=24,5$ & $\mathrm{a}=25,0$ \\
\hline $\begin{array}{l}\text { Height of the lowest } \\
\text { posts, mm }\end{array}$ & $\mathrm{h}_{1}=4,4$ & $\mathrm{~h}_{1}=4,8$ \\
\hline $\begin{array}{l}\text { Height of the medium } \\
\text { post, mm }\end{array}$ & $\mathrm{h}_{2}=7,1$ & $\mathrm{~h}_{2}=6,9$ \\
\hline $\begin{array}{l}\text { The gap between the } \\
\text { posts, mm }\end{array}$ & $\mathrm{l}_{1}=7,9$ & $\mathrm{l}_{1}=7,6$ \\
\hline $\begin{array}{l}\text { The thickness of all } \\
\text { post, mm }\end{array}$ & $\mathrm{w}=3,8$ & $\mathrm{w}=4,0$ \\
\hline
\end{tabular}

The results were obtained using the developed mathematical technique and the finite integration technique in the operating X-band 8.0 - 8.5 GHz.

Table 2 compares the polariser's characteristics for the mathematical model and the numerical model by finite integration technique.

The small differences in sizes and characteristics given in the tables can explain that the mathematical and numerical models are based on different numerical methods. As we can see, the matching and polarisation characteristics of the mathematical model and numerical model simulated using finite integration technique coincide with relatively high accuracy.
Table 2 - Characteristics of the optimal X-band waveguide iris polarizer obtained by the mathematical model and the numerical model.

\begin{tabular}{|c|c|c|}
\hline Characteristic & $\begin{array}{c}\text { Mathematical } \\
\text { model }\end{array}$ & $\begin{array}{c}\text { Numerical } \\
\text { model }\end{array}$ \\
\hline $\begin{array}{c}\text { Differential phase } \\
\text { shift }\end{array}$ & $90^{\circ} \pm 4,7^{\circ}$ & $90^{\circ} \pm 5,2^{\circ}$ \\
\hline VSWR & 1,29 & 1,3 \\
\hline Axial ratio & $0,77 \mathrm{~dB}$ & $0,81 \mathrm{~dB}$ \\
\hline XPD & $29,0 \mathrm{~dB}$ & $26,5 \mathrm{~dB}$ \\
\hline
\end{tabular}

\section{CONCLUSIONS}

The article suggests the new waveguide polarizer with posts, which improves the information resources economy in satellite information systems. The polariser has a compact design and allows to tune its characteristics by adjusting the positions simply. We proposed a new mathematical model to analyze and optimize the polarizer based on a square waveguide with three posts in the frequency range from $8.0 \mathrm{GHz}$ to $8.5 \mathrm{GHz}$. The model is based on the general wave scattering matrix of the device. The model allows optimizing its electromagnetic characteristics by changing the design parameters. To compare the results, a numerical model based on the finite integration method was applied to calculate a polarizer's performance. Obtained by both model's products are in good agreement with each other.

The developed square waveguide polarizer with three posts provides the following characteristics. The range of change of the introduced differential phase shift is $90^{\circ} \pm 5.2^{\circ}$. The developed polariser provides VSWR less than 1.3. The axial ratio is less than $0.81 \mathrm{~dB}$. XPD of the waveguide polarizer is higher than $26.5 \mathrm{~dB}$. Developed square waveguide polarizer with three posts can be widely applied in dual-polarization satellite communication systems to improve their information resources economy.

\section{REFERENCES}

1. Bulashenko, A. V. (2020). Evaluation of D2D Communications in 5G networks. Visnik NTUU KPI. Seriia - Radiotekhnika, Radioaparatobuduvannia, 81, 21-29.

2. Gladun, V. V. \& Bulashenko, A. V. (2019). Obtaining of high quality 5G network with D2D technology. Retrieved from https://ela.kpi.ua/bitstream/123456789/35676/1/RTPSAS_2019_s1_t16.pdf

3. Bulashenko, A. V. (2020). Resource allocation for low-power devices of M2M technology in 5G networks. KPI Science News, 3, 7-13. doi: 10.20535/kpi-sn.2020.3.203863 
4. Myronchuk, O., Shpylka, O., \& Zhuk, S. (2020). Two-Stage Channel Frequency Response Estimation in OFDM Systems. Path of Science, 6(2), 1001-1007. doi: 10.22178/pos.55-1

5. Myronchuk, O. Y., Shpylka, O. O., \& Zhuk, S. Y. (2019). Channel frequency response estimation method based on pilot's filtration and extrapolation. Visnik NTUU KPI. Seriia - Radiotekhnika, Radioaparatobuduvannia, 78, 36-42.

6. Gao, S., Luo, Q., \& Zhu, F. (2014). Circularly polarized Antennas Theory and Design. Chichester: John Wiley and Sons.

7. Stutzman, W. L. (2018). Polarization in Electromagnetic Systems. Norwood: Artech House.

8. Dubrovka, F. F., \& Piltyay, S. I. (2017). Novel high performance coherent dual-wideband orthomode transducer for coaxial horn feeds. 2017 XI International Conference on Antenna Theory and Techniques (ICATT). doi: 10.1109/icatt.2017.7972642

9. Piltyay, S. I. (2014). Enhanced C-band coaxial orthomode transducer. Visnik NTUU KPI. Seriia Radiotekhnika, Radioaparatobuduvannia, 58, 27-34.

10. Virone, G., Tascone, R., Peverini, O. A., Addamo, G., \& Orta, R. (2008). Combined-Phase-Shift Waveguide Polarizer. IEEE Microwave and Wireless Components Letters, 18(8), 509-511. doi: 10.1109/lmwc.2008.2001005

11. Piltyay, S. I., Bulashenko, A. V., \& Demchenko, I. V. (2020). Waveguide Iris Polarizers for Ku-band Satellite Antenna Feeds. Journal of Nano- and Electronic Physics, 12(5), 05024-1-05024-5. doi: 10.21272/jnep.12(5).05024

12. Bulashenko, A. V, Piltyay, S. I. \& Demchenko, I. V. (2020). Optimization of a polarizer based on a square waveguide with irises. Science-Based Technologies, 47(3). doi: 10.18372/23105461.47.14878

13. Piltyay, S. I. \& Dubrovka, F. F. (2013). Eigenmodes analysis of sectoral coaxial ridged waveguides by transverse field-matching technique. Part 1. Theory. Visnyk NTUU KPI. Seriia - Radioteknika Radioaparatobuduvannia, 54, 13-23.

14. Dubrovka, F. F., \& Piltyay, S. I. (2014). Eigenmodes of coaxial quad-ridged waveguides. Theory. Radioelectronics and Communications Systems, 57(1), 1-30. doi: 10.3103/s0735272714010014

15. Dubrovka, F. F., \& Piltyay, S. I. (2014). Eigenmodes of coaxial quad-ridged waveguides. Numerical results. Radioelectronics and Communications Systems, 57(2), 59-69. doi: 10.3103/s0735272714020010

16. Piltyay, S. I. (2017). High performance extended C-band 3.4-4.8 GHz dual circular polarization feed system. 2017 XI International Conference on Antenna Theory and Techniques (ICATT). doi: 10.1109/icatt.2017.7972644

17. Dubrovka, F. F. \& Piltyay, S. I. (2012). Prediction of Eigenmodes Cutoff Frequencies of Sectoral Coaxial Ridged. Retrieved from http://ena.lp.edu.ua/bitstream/ntb/14306/1/124.pdf

18. Lech, R., \& Mazur, J. (2004). Propagation in rectangular waveguides periodically loaded with cylindrical posts. IEEE Microwave and Wireless Components Letters, 14(4), 177-179. doi: 10.1109/lmwc.2004.827106

19. Zhu, Q. C., Williamson, A. G., \& Neve, M. J. (2007). Reactance of Posts in Circular Waveguide. IEEE Transactions on Microwave Theory and Techniques, 55(8), 1685-1688. doi: 10.1109/tmtt.2007.901605

20. Sharma, S. B., Singh, V. K., Dey, R., \& Chakrabarty, S. (2009). Analysis of a Post Discontinuity in an Oversized Circular Waveguide. IEEE Transactions on Microwave Theory and Techniques, 57(8), 1989-1995. doi: 10.1109/tmtt.2009.2025448

21. Roelvink, J., \& Williamson, A. G. (2010). Three Transverse Cylindrical Posts in a Rectangular Waveguide. IEEE Microwave and Wireless Components Letters, 20(5), 253-255. doi: 10.1109/lmwc.2010.2045578 
22. Casaletti, M., Sauleau, R., Ettorre, M., \& Maci, S. (2012). Efficient Analysis of Metallic and Dielectric Posts in Parallel-Plate Waveguide Structures. IEEE Transactions on Microwave Theory and Techniques, 60(10), 2979-2989. doi: 10.1109/tmtt.2012.2209449

23. Archemashvili, E., Yasumoto, K., Jandieri, V., Pistora, J., Maeda, H., \& Erni, D. (2020). Numerical Analysis of Dielectric Post-Wall Waveguides. 2020 International Workshop on Antenna Technology (iWAT). doi: 10.1109/iwat48004.2020.1570608549

24. Chittora, A., \& Yadav, S. V. (2020). A Compact Circular Waveguide Polarizer with Higher Order Mode Excitation. 2020 IEEE International Conference on Electronics, Computing and Communication Technologies (CONECCT). doi: 10.1109/conecct50063.2020.9198499

25. Deutschmann, B., \& Jacob, A. F. (2020). Broadband Septum Polarizer With Triangular Common Port. IEEE Transactions on Microwave Theory and Techniques, 68(2), 693-700. doi: 10.1109/tmtt.2019.2951138

26. Dubrovka, F. F., Piltyay, S. I., Dubrovka, R. R., Lytvyn, M. M., \& Lytvyn, S. M. (2020). Optimum Septum Polarizer Design for Various Fractional Bandwidths. Radioelectronics and Communications Systems, 63(1), 15-23. doi: 10.3103/s0735272720010021

27. Kirilenko, A. A., Steshenko, S. O., Derkach, V. N., \& Ostryzhnyi, Y. M. (2019). A Tunable Compact Polarizer in a Circular Waveguide. IEEE Transactions on Microwave Theory and Techniques, 67(2), 592-596. doi: 10.1109/tmtt.2018.2881089

28. Agnihotri, I., \& Sharma, S. K. (2019). Design of a Compact 3-D Metal Printed Ka-band Waveguide Polarizer. IEEE Antennas and Wireless Propagation Letters, 18(12), 2726-2730. doi: 10.1109/lawp.2019.2950312

29. Sellal, K., Talbi, L., Denidni, T., \& Lebel, J. (2006). A New Substrate Integrated Waveguide Phase Shifter. 2006 European Microwave Conference. doi: 10.1109/eumc.2006.281184

30. Polo-Lopez, L., Masa-Campos, J. L., \& Ruiz-Cruz, J. A. (2017). Design of a reconfigurable rectangular waveguide phase shifter with metallic posts. 2017 12th European Microwave Integrated Circuits Conference (EuMIC). doi: 10.23919/eumic.2017.8230730

31. Piltyay S. I., Sushko O. Yu., Bulashenko A. V., Demchenko I. V. (2020). Compact Ku-band iris polarizers for satellite telecommunication systems. Telecommunications and Radio Engineering, 79(19), 1673-1690. doi: 10.1615/TelecomRadEng.v79.i19.10

32. Piltyay S. I., Bulashenko A. V., Demchenko I. V. (2020). Analytical synthesis of waveguide iris polarizers. Telecommunications and Radio Engineering, 79(18), 1579-1597. doi:

10.1615/TelecomRadEng.v79.i18.10

33. Piltyay S. I. (2012). Numerically effective basis functions in integral equation technique for sectoral coaxial ridged waveguides. 14-th International Conference on Mathematical Methods in Electromagnetic Theory. doi: 10.1109/MMET.2012.6331195

34. Dubrovka F., Piltyay S., Sushko O., et al. (2020). Compact X-band stepped-thickness septum polarizer. IEEE Ukrainian Microwave Week (UkrMW). doi:

10.1109/UkrMW49653.2020.9252583

35. Dubrovka, F., Martunyuk, S., Dubrovka, R., Lytvyn, M., Lytvyn, S., Ovsianyk, Y., ... Zakharchenko, 0. (2020). Circularly Polarised X-Band H11- and H21-Modes Antenna Feed for Monopulse Autotracking Ground Station : Invited Paper. 2020 IEEE Ukrainian Microwave Week (UkrMW). doi: 10.1109/ukrmw49653.2020.9252600

36. Bulashenko A. V., Piltyay S. I., Kalinichenko Y. I., Bulashenko O. V. (2020). Tunable square waveguide polarizer with irises and posts. Technical Engineering, 86(2), 108-116. 